\title{
A study on the onset date of boreal fall rainfall season of India
}

\author{
B.V. Charlotte ${ }^{1}$, Gibies George ${ }^{2}$ and R.D. Ruchith ${ }^{3}$ \\ ${ }^{I}$ PI, DST, Women Scientist Scheme, CUSAT ${ }^{2,3}$ Indian Institute of Tropical Meteorology
}

\begin{abstract}
Southern Peninsular India and Sri Lanka experience the boreal fall monsoon during October to December. Boreal fall monsoon is the season between boreal summer and boreal winter when the ITCZ locate near to Sri Lanka and southern Peninsular India. The onset date of NE monsoon over SP is a matter of pivotal interest to the people of Tamil Nadu because they are in the leeward side of Western Ghats during the southwest monsoon. Large arable land, dearth of rivers, thickly populated peasants who depends on rain fed farming everything aggravates their thirst for rain. To quench the thirst the boreal fall begins in the coast of Tamil Nadu first and advances inward even though the wind comes from north. It is difficult to find a trend in onset date of boreal fall of SP. Raj (1992) defines the onset of Northeast monsoon over southern peninsular India based on the synoptic features. Later studies suggest that the onset of NE monsoon in India is calculated as the day on which central Tamil Nadu receives rain more than $5 \mathrm{~mm}$ (Raj 2011). At this juncture this is a clear cut attempt to find out precisely the genuine date of NE monsoon onset over the Southern Peninsular India based on area average rainfall over SP and based on the most prevalent wind at $850 \mathrm{H} \mathrm{pa}$. Date of area average onset, in this study, is defined as the first date on which the daily mean rainfall amount over SP becomes greater than the mean climatology value and the area average surface wind is purely easterly. Verification and validation of the area average onset date of northeast monsoon rainfall is done by calculating the deviation from the date of onset over coastal Tamil Nadu determined by Raj (1992) for the years up to 1990 and that of IMD for years after 1990.
\end{abstract}

Key Words: - area average, Boreal fall, monsoon, onset, Southern Peninsular India.

\section{Introduction}

As the sun moves SH the cool air over Indian Land mass sweeps down to Indian Ocean picking up moisture from Bay of Bengal giving rain to southern Peninsular India and parts of Sri Lanka which is known as the NE monsoon of India. But in S. Asia NE monsoon take place from December to early March. The sustaining high pressure system in this region at that time give rise to a jet stream which later splits into subtropical jet and polar jet stream. It is this subtropical flow of air directs the north easterly winds to blow across S Asia and this dry air create clear sky over India. But in mean time a low pressure system develops over SE Asia and Australia which gradually develops into a monsoon trough. The maritime continent generally experience dry summer and wet boreal winter. Complex terrain and reversing monsoon wind across the equator intertwine summer and winter monsoon regimes. The winter monsoon regime includes places in the NH but summer monsoon regime never goes to southern latitudes (Chang et al 2005). The changeover of the monsoon during the transition period is quite asymmetric and really hectic. The redistribution of land-ocean mass and its thermal memories could be the reason behind this enigma. Naturally the sea level pressure pattern and associated wind flow can be traced to a great extent to explain the scene.

The onset of NE monsoon can be defined as the first occurrence of broad scale wet conditions with a minimum sustenance of 3-4 days in conjunction with easterly wind conditions at $850 \mathrm{H}$ pa over the experimental area. Most probably it will be coinciding with deep westerly in the upper region of troposphere. It is usual to see the prevalence of MJO in connection with the onset of monsoon (Mathew Wheeler 2002). Formation of large scale synoptic disturbances in Indian Ocean or Bay of Bengal due to build up of planetary scale and landsea temperature gradients reaching a critical stage can work out as the triggering mechanism for monsoon onset. Travelling highs and lows towards the south over the sp can be configured during the onset period. The passage of the trough region of the equator wave can also be assigned with the onset of monsoon. Instability occurring in the lower troposphere in synchronization with the movement of frontal formation in the upper troposphere can be another onset reason (Noel Davison et al 2007). In winter phase of Indian monsoon the positive feedback due to cool SST in the Eastern Indian Ocean and the prevailing easterly anomaly, subsiding upwelling in the Sumatra coast leads to lack of communication between the subsurface and surface water, slacking down surface wind together heats up the eastern IO offers a possible link between the onset of NE monsoon of SP to ENSO activities of Pacific Basin (Wu, and Ben 2007).

During boreal winter the presence of MJO and its triggering capacity for a winter monsoon onset can be traced just by studying only the horizontal wind component, whereas its influence in summer monsoon onset is more complicated with the presence of rotational wind components extending northwards and westwards ( $\mathrm{Li}$ 
2010). Hence the winter monsoon onset study can be made easy by following the dominant surface wind analysis in the area

Indian winter monsoon attributes more coherently with ENSO phase when compared with Indian summer monsoon. This may be largely due to the masking of internal atmospheric dynamics during the summer phase. The convection -wind-evaporation system around SP has to be taken into consideration as it holds fine feed back to any monsoon onset processes. IO surface heat flux and west Pacific ENSO phase keep good link via atmospheric abridge (Michael A Alexander 2002). As long as the IO-ENSO amplitude is less the predictability of winter monsoon of SP with ENSO will be naturally more. The transposition of local Hadley circulation can give good implementation about the amount of rainfall during the winter monsoon. The sinking process displayed by the troposphere, weakening of local Hadley Circulation around $15^{\circ} \mathrm{N}$ and $20^{\circ} \mathrm{S}$, marginal shifting in the ascending branch of Walker circulation are the three distinct direct features controlling rain amount of Asia due to ENSO (Lau et al 2001). During El Nino Walker circulation shifts eastward subsidence and pressure increase co-occur in the east IO leading to marginal decrease in winter rain across SP. The increased SST over Pacific at this time is followed with a decrease in SST around Indonesian region. The seasonally varying air-sea interaction processes of East Indian Ocean accompanied with local SST and rainfall being complimented with ENSO makes things far easier to reach at a reasonable prediction about the onset date of winter monsoon over SP. Darwin's surface pressure and the sudden reversal of wind pattern in the lower troposphere are the two salient features that can be exploited towards the successful prediction of winter monsoon. Australia the rainfall leading to the onset is absolutely correlated to the El Nino events but the amount of rain throughout the season cannot be assumed from SOI (Hendon et al 2011). Since they can more successfully predict the winter onset of monsoon simply based on ENSO it is high time we should look at the feasibility of doing the same over SP rather than depending on the conventional methods and clinging to the age old attitude that onset in SP take place only if it is raining at central Tamil Nadu. Because it is a proved fact that all other subdivisions of SP Kerala, coastal Karnataka, parts of Andhra Pradesh etc display exactly the same features during winter monsoon and get adequate winter rain before Central Tamil Nadu started getting it. Moreover we have to keep in mind this is a region over the earth thickly populated with poor uneducated farmers who simply depends on rain for cultivation and their daily sustenance. It is even more practical to find out the onset date separately for east, west and central part of SP and to calculate the standard deviation in the onset dates and hence to arrive at a precise date which will be helpful to make a reliable prediction in this regard understanding the sanctity and importance of issue.

\section{Material and methods}

The data utilized is daily gridded rainfall data from Indian Meteorological Department and other meteorological parameters like SST, SLP and zonal wind at $850 \mathrm{H}$ pa were taken from NCEP/NCAR (National Center for Environmental Prediction/ National Center for Atmospheric Research) reanalysis data downloaded from internet (Collins D 1996). Southern peninsular India region enclosed by $10^{\circ} \mathrm{N}, 13^{\circ} \mathrm{N} \& 70^{\circ} \mathrm{E}, 80^{\circ} \mathrm{E}$ is taken as the study area.

The tenth conference of forecasting officers of IMD (1987) suggested some criteria for the declaration of onset of NE monsoon over Tamil Nadu. These suggestions were subsequently accepted by IMD. Later Raj modified the rules to determine the Coastal Tamil Nadu onset of NE monsoon and finally developed a more practical method in 1992 (Raj 1992). In this work while we were trying to see how accurate the current methodology that we are following, we studied the validity using area average rainfall onset for years from 1960 up to 2003. Until 1990 the criteria for onset suggested by Raj is used for coastal onset and later years the IMD declaration of onset obtained from RMC Chennai website is utilised. The deviation of area average onset date with the above onset dates is done for each year between 1960 and 2003 to check the validity of area average onset. The distribution of SST, SLP and Wind component on the date of area average onset of NE monsoon, five days before the onset as well as five days after the onset are analysed to notice the changes in those parameters during the area average onset of North East monsoon over southern peninsular India.

\section{Result and discussion}

The area average onset of rain in this study is taken as the date in which the daily area average of boreal rain supersedes the climatology mean rainfall. The histogram of area average rainfall over SP (Fig: 1) claims that the onset is often found happening between October 13 th and $15^{\text {th }}$. If late, there are also equally good chances of onset getting delayed to October $25^{\text {th }}$ and $27^{\text {th }}$. Fifty eight years analyses emphasize the probability of boreal fall onset before the $27^{\text {th }}$ of October itself and $75 \%$ years it fell in between October 10 and $20^{\text {th }}$. The chances of having the onset in November can be ignored. Inter-annually and intra-seasonally when checked SP enjoys maximum winter rain in this month (George, Charlotte et al 2011, Charlotte et al 2012). Close to the onset the area get wide spread rain which decreases in the subsequent months and somewhat extinct by the end of December. So early onset of monsoon often found results in abundant rain unlike a belated one. In order to 
get much more good insight the deviation of area average onset with the coastal onset is also calculated. The histogram points (Fig: 2) out that area average onset clearly taking place much ahead of coastal onset in majority of the study period. Whenever the coastal onset took place earlier than the area average onset of boreal fall of SP it was invariably leading to drought conditions. The sanctity of having better yardsticks for the declaration of onset reflects in this observation. It in itself is a good implication for exploring a brand new modern methodology for the prediction of onset in a more precise way rather than following statistical analysing techniques.

The individual years that showed late onset example 1963, 1974 and 2000 along with its SST, SLP, horizontal component of wind and rain distribution is displayed in the fig: 3, 4 and 5 respectively. Similarly early onset years of 1969, 1976 and 1981 with all above features are shown in fig: 6, 7 and 8 for individual scrutiny. Fig: 9 depict the climatology of SLP over Indian Ocean right on the day of onset of boreal fall of SP, five days ahead of it as well as five days after the onset. The most conspicuous feature of the SLP figure is the increasing high pressure formation of Siberian High to $1016 \mathrm{H}$ pa and a simultaneous depression of $1009 \mathrm{H} \mathrm{pa}$ developing close to Tamil Nadu coast in Bay of Bengal. The sustaining high pressure over the Somalia coast of Arabian Sea during this period helps to converge and focus the moistened air to SP. The climatology value of SST (Fig: 10) in central Bay of Bengal on the onset day is $301 \mathrm{~K}$ whereas the surrounding region equatorial west Pacific, China Sea and N Bay of Bengal are warmer with a warm pool existing in the Head Bay. The warm pool vanishes as soon as the rain begins, may be due to the cooling by precipitation. (Fig: 11) show the interesting scenes of reversal of surface wind in the Arabian Sea and Bay of Bengal. The westerly wind prevailing in Indian Ocean withdraw its core southward beyond $5 \mathrm{~N}$ giving way to strong easterly from East China Sea. Complete withdrawal of westerly wind take place first in Arabian Sea and gradually the easterly joins with China Sea. Even though the easterly wind is first born in Arabian Sea it is the east coast of the peninsula that is exposed to boreal fall first. But of course who comes next is unpredictable. Thus area average onset and coastal onset of NE monsoon were found to be exactly on the same day for nine years, fifteen years goes within the limit of one day deviation and Sixteen years showed the deviation within seven days. Just seven years displayed the deviation beyond seven days. During onset there is a development of low pressure area over Bay of Bengal coast of Southern peninsular India. North Indian Ocean comprising Bay of Bengal and Arabian Sea exhibit warm SST. Easterly wind anomaly begins due to warming up of African continent. It first replaces the westerly of Arabian Sea and extends up to the west coast of Bay of Bengal. The onset of North East monsoon is marked with the establishment of strong easterly wind over Coastal Tamil Nadu and wide spread heavy rainfall.

\section{Conclusion}

The onset of boreal fall of SP is remarkable with the presence of strong easterly and heavy precipitation over coastal Tamil Nadu region. The area average onset of boreal fall of SP happens well ahead than coastal onset in most of the study period. If at all the area average rain fall onset is happening late to coastal onset it normally lead to drought conditions. The onset is generally found in between $10^{\text {th }}$ and $20^{\text {th }}$ of October. Earlier the onset more abundant is the rain. Different air-sea parameters sustaining in and around SP is studied to understand the features leading to the onset of boreal fall. Increase in precipitation and reversal of the wind are two obvious features if we plan to depend on it manually for the onset. Establishment of low pressure in Bay of Bengal, reversal of westerly from Arabian Sea to East China Sea, existence of comparatively low temperature in the central Bay of Bengal are some of the important features attached to boreal fall onset.

The statistical method of deriving onset days based on Central Tamil Nadu getting $5 \mathrm{~mm}$ of rain seems to be inadequate, irrelevant and little ingenious in this modern era. Calculating area average is a simple alternative giving equal weight age to different parts involved in SP in deciding the onset date. Just for calculation of the onset day the methodology that we follow is found to be ingenious then what is its reliability when it comes to predictive terms. Exploiting the strong ENSO boreal fall relation of SP, the possibility of arriving at more accurate onset prediction must be experimented taking into consideration of the deplorable condition of the farmers living in the area. At this juncture it is feasible to follow the path of more developed neighbouring countries that successfully does winter monsoon prediction decades back onwards.

\section{Acknowledgement}

Authors thank mysterious guiding throughout the writing of the manuscript. For the funding of the work we are thankful to DST women Scientist Scheme (WOS-A) and the facilities provided by the computer labs of Department of Environmental Science CUSAT and Department of Atmospheric Science CUSAT. 


\section{References}

[1] Chang C. P, Z Wang, and C.H. Liu (2005) Annual cycle of south east Asia- Maritime continent rainfall and asymmetric monsoon transition $j$. Climate $18 \mathrm{pp} 28$

[2] Mathew C Wheeler (1992) - Modulating South Indian Ocean Tropical Cyclones by the Madden-Julian Oscillation and Convectively Coupled Equatorial Waves. J. Research in Meteorological Soc., 137: 673689. Q 7-301

[3] Noel E Davison, Kevin J and Michel Reeder (2007) Tropical interaction during onset of the Australian monsoon; Reanalysis Diagnostics and idealized dry simulations $j$. Atmospheric Sciences 64 pp.3475- 3498

[4] Wu and Ben 2007 Impacts of Indian Ocean in the Australian summer monsoon -ENSO relationship J Climate 17 pp 3037-3054.

[5] Michael A. Alexander (2002) The Atmospheric Bridge: The Influence of ENSO on Air-Sea Interaction over the Global Oceans journal of Climate 15 pp 2205-2231.

[6] Lau, K.-M., and H. T. Wu, 2001: Principle modes of rainfall-SST variability of the Asian summer monsoon: A reassessment of the monsoon-ENSO relationship. J. Climate, 14, 2880-2895.

[7] Hendon, Lim and Mathew Wheeler (2011) Seasonal study of Australian Summer Monsoon. THE GLOBAL MONSOON SYSTEM: RESEARCH AND FORECAST, World Scientific Series on Asia-Pacific Weather and Climate, Vol. 5 pp73-85

[8] IMD Chennai; IMD site of Chennai region - www.imdchennai.gov.in/northeast monsoon.htm

[9] Collins, D. NCEP/NCAR 40-year reanalysis project, Bull. Amer. Met. Soc, 77(1996) 437-471.

[10] Indian Met. Dept., 1973, "Northeast Monsoon", FMU report IV, 18.4

[11] Raj Y.E.A., 1992, "Objective determination of northeast monsoon onset dates over coastal Tamil Nadu for the period 1901-190", Mausam, 43, 273-282.

[12] Raj Y.E.A., 2011, an overview of Indian North East Monsoon, INMERC, pp 3-15

[13] George, G, B.V. Charlotte, R.D. Ruchith and Suguna Yesodharan (2011) Inter-annual variation of north east monsoon rainfall over southern peninsular India Indian Journal of Geo-Marine Science, 40(1) 98-104.

[14] Charlotte, B V, E.K. Simon, Gibies George, R.D Ruchith and S Yesodharan (2012) Intra-seasonal oscillation of NE monsoon over southern peninsular India, an investigation, International journal of Scientific and Research Publications vol. 2 August $8^{\text {th }}$ issue. 